Sciendo

\title{
What is Existence?
}

\author{
João Branquinho
}

University of Lisbon

Disputatio Vol. 4, No. 34

December 2012

DOI: 10.2478/disp-2012-0021

ISSN: 0873-626X 


\title{
What Is Existence? ${ }^{1}$
}

\author{
João Branquinho \\ University of Lisbon and LanCog Group \\ BIBLID [0873-626X (2012) 34; pp. 575-590]
}

\section{Introduction}

This paper has a negative and a positive claim. The negative claim is that the Frege-Russell account of existence as a higher-order predicate is mistaken and should be abandoned, even with respect to general statements of existence such as "Flying mammals exist" (where statements of this sort are supposed to be best accommodated by the account). The Frege-Russell view seems to be supported by two ideas. First, the idea that existence is entirely expressed by the existential quantifier of standard predicate logic. Second, the idea that the existential quantifier is a higher-order predicate, a predicate of predicates, not of individuals. I think that both ideas are wrong but will focus on the latter. By construing prima facie first-order statements such as "Flying Mammals exist" as higher-order predications such as "The Fregean Concept Flying Mammal maps at least one individual onto the True", the Frege-Russell view commits one - merely on the basis of the meaning it assigns to the existence predicate - to abstract objects such as concepts (Gottlob Frege), or propositional functions (Bertrand Russell), or classes (Rudolf Carnap), or properties, kinds, and so on. This cannot be right, I think.

The positive claim of the present paper is that, at least in the context of first-order discourse, the existence predicate is just what it seems to be: a bona fide first-order predicate (pace Kant, Hume, Frege, Russell and others). Three important ideas about existence are shared with the Frege-Russell conception of existence, though.

\footnotetext{
${ }^{1}$ I have been strongly influenced in this paper by the views advanced by Nathan Salmon, mainly in Salmon 1987 and Salmon 1998. The views endorsed here are similar to his views, but my motivation is different.

Disputatio, Vol. IV, No. 34, December 2012
} 
(1) Being and existence are one and the same thing: there is no difference between "Unicorns are not", or "There are no unicorns", and "Unicorns do not exist", or "There exist no unicorns". (2) To be is to be the value of a bound variable, to belong to a domain of quantification (Willard Quine). (3) Anti-Meinongianism, the idea that there are no non-existent objects (Russell). However, we diverge from the Frege-Russell tradition with respect to the following claim. (4) The best concept of existence, in the sense of the one that is best understood and best enables us to formulate ontological disputes, is a purely logical first-level concept defined in terms of existential quantification and identity. First-order statements of existence and non-existence like "Flying Mammals exist" and "Unicorns do not exist" are accordingly taken at face value and analyzed in terms of a logical first-order predicate of existence, the predicate "is (identical to) something". Reasons are given to prefer this notion of existence to other first-order non-logical notions that have been proposed in the literature, notions characterized in terms of predicates such as "is in space-time", "is concrete", "is causally efficacious", "is actual", "is real", etc.

We will also reflect upon the concept of existence by studying the logical form of statements of existence and non-existence, statements such as

Flying mammals exist

Unicorns do not exist

Venus (the planet) exists

Vulcan (the planet) doesn't exist

We are particularly interested in the logical and semantic status of the existence predicate involved therein. We want to determine what existence predicate we should have at the level of logical form that would correspond to the grammatical predicate "exist(s)" at the surface level.

The issue about the logical form of existence statements is a vexed issue in contemporary philosophical semantics, an issue that is far from having received a satisfactory treatment. On the other hand, I think that the search for an adequate existence predicate can only be correctly carried out if we first provide answers to a salient set of 
general questions about existence. In what follows I introduce three such questions and three theses I want to endorse in answering them, such theses shaping the subsequent adoption of an appropriate existence predicate.

Availing ourselves of an appropriate existence predicate is highly important for purposes of meta-ontology, for it allows us to describe ontological disagreements, disagreements about what exists, as they should be viewed (at least sometimes): genuine disagreements, not merely verbal or terminological ones.

\section{Existence and quantification}

Here is the first of our three questions concerning existence.

\section{Question 1 - Existence and Quantification}

Is there any relation between the concept of existence and the concept of quantification, especially existential quantification?

The answer to this question that I would like to favor is this.

Thesis 1: Existence is not entirely expressed by the existential quantifier $\$$, but there is an important connection between the two concepts: the concept of existential quantification should be seen as playing a central role in a correct characterization of the concept of existence (details later)

Of course, several philosophers have rejected Thesis 1. On one side of the opposition is the Frege-Russell view, also famously endorsed by Quine (Quine 1980: 12-13), on which existence is fully represented by the existential quantifier. We will come back to the Frege-Russell view later on. On the other side of the opposition is Meinongianism, defined in general as the view that some objects do not exist.

Meinongianism comes in a variety of versions, including the original views of Russel in Principles of Mathematics (Russell 1903), Terence Parsons's views in Non-Existent Objects (Parsons 1980), and more recent versions developed by Richard Routley (Routley 1980) and Graham Priest (Priest 2005), known as Noneism (David Lewis coined this term in Lewis 1990). However, all brands of Meinongianism have in common the rejection of any sort of explanatory link 
between the concepts of existence and quantification.

On the latter side of the opposition to Thesis 1 is also the apparently anti-Meinongian position recently advanced by Kit Fine (Fine 2009). Fine develops a set of interesting considerations with a view to rejecting any account of existence in terms of quantification. However, we believe it is wrong to separate in limine, from the point of view of explanation, these concepts. After all, there seems to be a strong intuitive sense in which the existential quantifier carries existential force, has ontological import. We regard as implausible the reading of $\exists$ as a merely "particular" quantifier (Priest), deprived of the ontological role of introducing at least one object of a domain of quantification. We prefer a moderate view, on which the existence predicate is still a logical predicate, but one only partially defined in terms of existential quantification (Thesis 1).

\section{Is existence a first-level concept?}

We turn now to our second question about existence.

\section{Question 2 - Is existence a (first-order) predicate?}

This is the old question of whether existence is, or can be a "real" predicate, a predicate like the others, a predicate of familiar things, a predicate like "flies", "is a mammal", "is famous", etc.

There are two extreme positions concerning this question, which I label the Old School and the Very Old School. We want to endorse the Very Old School, but let us take the Old School first.

\section{(a) The Old School}

This is basically the Frege-Russel conception of existence (See Russell 1988: 211 and Frege 1950: 64-65). It consists in giving a negative answer to Question 2 on the basis of two premises.

Premise 1: $\exists$ is a higher-order predicate, a predicate of predicates, never applicable to entities of level 0 or individuals.

Roughly speaking, individuals are those entities that, in spite of being able to belong to classes, to instantiate properties, to be members of species and kinds, to be subsumed by Fregean concepts, to 
be arguments of Russellian propositional functions, and so on, are not themselves classes, properties, species, kinds, Fregean concepts, propositional functions, and so on.

Premise 2: The already mentioned claim that the concept of existence is entirely expressed by $\exists$.

These two premises entail the following claim, a claim also endorsed (at least in its negative version) by Kant and Hume.

Conclusion: Existence is invariably a higher-order predicate, never a predicate of individuals.

Before critically examining the Old School, let us introduce the Very Old one.

\section{(b) The Very Old School}

This position gives an affirmative answer to Question 2 and consists in the following thesis.

Thesis 2: Existence is a first-order predicate.

(As we shall soon see, we must be careful here and take Thesis 2 as presupposing a restriction of the universe of discourse to individuals.)

The claim that existence is, or can be, a first-order predicate is endorsed in all varieties of Meinongianism. It is also endorsed on the already mentioned, non- Meinongian, account proposed by Fine. It is further endorsed on the present view, which is not Meinongian either (see below). It is therefore a mistake to think that rejecting the claim that existence is a higher-order predicate entails embracing Meinongianism.

As noted, Thesis 2 has to be subjected to the important qualification that, in the context of our discussion of Question 2, we are dealing only with first-order discourse, with statements about individuals. Thus, the following statements would presumably be excluded from our discussion, for they are higher-order (or so we assume for the sake of argument): 
Wolf and dog inter-breed.

There are animal species on the verge of extinction.

Humility is rare, cowardice despicable.

The class of prime numbers is infinite.

In contrast, the following statements would presumably be admitted (or so we assume for the sake of argument):

The wolf is more aggressive than the dog.

The dog has warm blood.

There are flying mammals.

Humility is a virtue.

Now if the above qualification were not made, Thesis 2 would be promptly refuted on the basis of statements such as

Primary colors exist.

The Dodo bird no longer exists.

Indeed, the existence predicate is clearly second-order here.

It is crucial to note that, even under the restriction to a domain of individuals, existence is still a higher-order predicate on the FregeRussell view. Let us check this by considering seemingly first-order statements such as

(1) Flying mammals exist.

(2) Unicorns do not exist.

The Frege-Russell analysis is carried out in two steps. First, in the light of the Frege-Russell claim that existence is fully expressed by the existential quantifier, such statements are analyzed as

(1)' Something is a flying mammal

(1)' $\exists x$ Flying Mammal $\mathrm{x}$

(2)' Nothing is a unicorn

(2)' $\neg \exists x$ Unicorn $x$ 
Second, the latter statements are in turn paraphrased into secondorder statements such as (these are only examples)

(1)" The class of flying mammals is not empty

(1)" The property of being a flying mammal is instantiated

(1)" The Fregean concept Flying Mammal maps at least one individual onto the True

(1)" The propositional function Flying Mammal is possible

(2)" The class of unicorns is empty

(2)" The property of being a unicorn has no instances

(2)" The Fregean concept Unicorn maps no individual onto the True

(2)" The propositional function Unicorn is impossible

We believe that the second step of the Frege-Russell analysis is profoundly mistaken, that the proposed paraphrase in terms of higherorder predications is wrong.

Here are four objections to the Frege-Russell view.

\section{Objection 1: Expressive Power}

The Frege-Russell account does not seem to have the means to express, in the language of the theory, some existence and non-existence claims to which it is manifestly committed. In particular, it does not seem to have the means to express the anti-Meinongian statement "Everything exists" or "There are no non-existent objects". It is hard to see how these statements could be analyzed in the Frege-Russell style, how the existential quantifier could here give way to an appropriate higher-order predicate.

\section{Objection 2: Ontological Inflation}

The Frege-Russell treatment of the existential quantifier as a higher-order predicate has immediate anti-nominalist consequences, or (if you prefer) immediate Platonist or Realist consequences, which cannot be right in my view. A true statement of existence like "Flying mammals exist" ontologically commits us not only to things that are mammals and fly (these are individuals and concrete items), but 
also to abstract objects such as classes, Fregean concepts, properties, propositional functions, etc. And even true statements of non-existence, such as "Unicorns do not exist", ontologically commit us to the very same sort of abstract objects (although they do not commit us to unicorns).

Note that we might have good reasons to introduce abstract objects, even of all the types in question, into our best ontology. But not merely on those grounds, not merely on the basis of a proposal about the meaning and logical form of statements of existence and non-existence.

\section{Objection 3: Slippery Slope}

This is an argument in the style of Frank Ramsey (see Ramsey 1925).

If a true predication of existence like "Flying mammals exist" were to be paraphrased into something like "The Fregean concept Flying Mammal maps at least one individual onto the True", then nothing would prevent us from paraphrasing in the same way virtually any predication, including common predications such as "Mammals have warm blood" and "Rover is a dog". The result would be something like "The Fregean concept Having Warm Blood maps onto the True any individual mapped onto the True by the Fregean concept Mammal" and "The Fregean concept Dog maps the individual Rover onto the True".

The same would go for paraphrases in terms of classes, properties, propositional functions, and so on. Any prima facie first-order predication would turn out to be, at bottom, higher-order in nature. I take it that this is a highly implausible consequence of the FregeRussell account of the existence predicate.

Objection 4: The Intuitive Criterion of Difference for Thoughts

This Fregean principle, as formulated by Gareth Evans (see Evans 1982: 21), states that thoughts or contents $\mathbf{p}$ and $\mathbf{q}$ are distinct if it is rationally possible to take conflicting propositional attitudes towards them, say believing $\mathbf{p}$ while not believing $\mathbf{q}$ or disbelieving $\mathbf{q}$, believing $\mathbf{p}$ while doubting $\mathbf{q}$, etc. Now it seems perfectly possible for a rational subject to accept "Flying mammals exist" and "Unicorns do 
not exist" but at the same time to be in doubt about, or even reject, their Fregean paraphrases "The Fregean concept Flying Mammal maps at least one individual onto the True" and "The Fregean concept Unicorn maps no individual onto the True". The subject might so proceed on the basis of strong nominalist convictions, or because she is just skeptical about entities such as Fregean concepts. And it does not matter at all if the subject is right or wrong in doing so. The same would go for paraphrases in terms of classes, properties, propositional functions, and so on.

\section{Existence and being}

We turn now to our third question about existence.

\section{Question 3 - Being and Existence}

What is the relation between being, in the sense of being something, being an object, and existing, or having existence? Does being transcend in any sense existence? Should we claim that something does not exist, that some objects do not exist? Or should we rather claim that everything exists, that every object exists?

On the most usual versions of Meinongianism, there are objects that do not exist: the realm of being, of what can be quantified over or referred to (roughly speaking), is broader than the realm of existence, of objects in space-time (roughly speaking). On other versions of Meinongianism, we have only the weaker claim that some objects do not exist (the so-called particular quantifier "some" having no ontological or existential import). This is the case of the original views of Meinong, since he posits objects that do not have any form of being, such as chimeras and impossible objects. And is also the case of the Noneist views of Routley and Priest (for the same reason).

Noneism has the advantage of keeping Meinongianism immune to what is often seen as a serious objection to the position, namely that the distinction it often makes between being and existence makes little sense. As Quine remarks (Quine 1980: 3; Quine 1969: 100), there is no discernible difference between statements such as "There are prime numbers" and statements such as "There exist prime num- 
bers". David Lewis (Lewis 1990) and Peter van Inwagen (van Inwagen 2008) argue in the same direction.

But there is another serious objection to Meinongianism, and this one also applies to the Noneist variety. The objection is that Meinongianism obliterates a distinction that should be made in any case between genuine reference, e.g. "The American who lives upstairs" (where the description has a referential use), and merely apparent reference, e.g. "The average American" or (perhaps) "My shadow". Meinongianism also obliterates, in the same vein, a distinction that should be made in any case between genuine quantification, e.g. (perhaps) "There are prime numbers", and merely apparent quantification, e.g. (perhaps) "There are intolerable fluctuations in the stock market". Such distinctions are obliterated on the Meinongian view because this view seems to be committed to the idea that any term that appears to denote something actually denotes something, and that any expression that appears to quantify over something actually quantifies over something. We find this idea unacceptable as it goes against basic Russelian wisdom. So we endorse the following antiMeinongian thesis with respect to Question 3:

Thesis 3: Everything exists, there are no non-existent objects

We introduce below further reasons for rejecting Meinongianism and accepting Thesis 3 .

\section{The existence predicate}

We note now that the existence predicate we are looking for will have to conform to Thesis 3, which means that it has to be an existence predicate $\mathbf{E}$ that satisfies the following principle

$$
\text { (E) } \forall \mathrm{xEx}
$$

In other words, we need an existence predicate that is true of every object and false of no object. That is to say, we want the extension of $\mathbf{E}$ to be the entire domain of quantification.

On the other hand, by Thesis 2, E has to be a first-order predicate (assuming a universe of discourse containing only individuals). Also, by Thesis $1, \mathbf{E}$ has to be a predicate partially definable in terms of 
existential quantification.

Finally, having our initial methodological remarks in mind, our existence predicate $\mathbf{E}$ should be conceptually clear and apt to correctly describe a wide variety of ontological disputes, disputes about what there is or exists, as they at least sometimes are, viz. as substantive disputes.

Now, the existence predicate $\mathbf{E}$ we are looking for, one that satisfies the set of Theses 1,2,3 and meets the above methodological requirements, is simply the familiar predicate_is something, _is identical to at least one object (See Quine 1969: 97; also Kripke 2011: 55, Footnote 6 and Salmon 1987:20-2). (Of course, I assume that our language contains the identity predicate among its logical constants.)

$$
E x=(d f) \exists y x=y
$$

Let us check this. If one is dealing with first-order discourse and our domain is a domain of individuals, then our existence predicate will invariably be a first-order predicate, a predicate of individuals, vindicating thus Thesis 2. On the other hand, our existence predicate is not primitive, since it is defined in terms of quantification and identity, vindicating thus Thesis 1 . Also, it is a purely logical predicate, as it is characterized in terms of logical concepts only. Finally, it is a predicate that is entirely in order from the point of view of conceptual clarity, at least to the extent that logical concepts are entirely in order from that point of view.

Notice that "Everything exists", in symbols $\forall \mathrm{xEx}$ or $\forall \mathrm{x} \exists \mathrm{y} \mathrm{x}=\mathrm{y}$, is a logical truth and thus (in some sense) a trivial truth. Our existence predicate is a tautologous predicate and therefore also a trivial predicate (in some sense). However, such triviality can be somehow mitigated if we notice that ontological disputes are not automatically solved on that basis (Quine 1980:1). To exist, or to be, is to belong to a domain of quantification, and everything belongs to a domain of quantification, but that does not by itself tell us what to include in the domain of quantification, it does not by itself tell us what we should put among everything. We might still want or not want to include mere possibilia, fictional objects, chimeras and other intentional objects, universals, numbers, material objects, arbitrary fusions of ma- 
terial objects, temporal parts, etc.

We go back to the Meinongian view now. What other choices would be available for a first-order existence predicate $\mathbf{E}$ ? Here is a list of some of the usual proposals, most of them having a clear Meinongian motivation.

(a) $E x=x$ is causally efficacious (Priest)

(b) $E x=x$ is actual (in the modal sense)

(c) $\mathrm{Ex}=\mathrm{x}$ is concrete

(c)' $\mathrm{Ex}=\mathrm{x}$ is in space-time (Russell)

(d) $E x=x$ is real, where "real" is a primitive predicate (Fine 2009: 168-9)

(e) $E x=x$ is a non-intencional object (MGinn 2000: 15-51)

The main problem with the Meinongian proposals (a)-(c)', and also with the quasi-Meninongian proposal (e), is a problem of meta-ontological inadequacy. Indeed, the characterizations proposed for the existence predicate $\mathbf{E}$ have the undesirable feature of entailing a rejection from the outset of a certain range of ontological positions, which would thus be counted as conceptually false, i.e. false merely in virtue of the concept of existence employed. Here are examples of such positions: "Universals exist", "Mere possibilia exist", "Classes exist", "Numbers exist". It might be replied that on the most usual versions of Meinongianism we could still have truths like "There are universals", "There are mere possibilia", "There are classes", "There are numbers", etc. But, as noted, the problem with those views is that they rely on a distinction between being and existence that it is hard to make sense of.

So the Meinongian view underlying proposals (a)-(c)' has immediate nominalist implications. On the other side, as we have seen, the Frege-Russell view has immediate anti-nominalist implications. Both are thus wrong for the same kind of reason.

The problem with proposal (d) is that it is not completely clear what "real" means; or, to be more cautious, one should at least say that its meaning is less clear than the meaning of our existence predicate.

I finish with a few brief remarks on logical form. How statements of existence and non-existence of central kinds should be analyzed 
on the present view?

With respect to statements of singular existence and non-existence, the answer is readily available.

Singular Existence: a exists

Ea, $\exists$ y a $=y$

Singular Non-existence: a does not exist

$\neg \mathrm{Ea}, \neg \exists \mathrm{y}$ a $=\mathrm{y}$

With respect to statements of general existence and non-existence, we need to be more careful. Take the former ones, first.

General Existence: Fs exist

This is a more complicated case, but for reasons given below we go for

$$
\exists \mathrm{x}(\mathrm{Fx} \wedge \exists \mathrm{yx}=\mathrm{y})
$$

A statement like "Ostriches are fast" is ambiguous between a universal quantification, "All ostriches are fast", an existential quantification, "Some ostriches are fast", and a generic, "Ostriches are typically fast". By analogy, a statement like "Flying mammals exist" admits two reading (excluding the generic reading for obvious reasons).

Reading 1: Every flying mammals exist

$$
\forall \mathrm{x}(\mathrm{MVx} \rightarrow \exists \mathrm{y}=\mathrm{y})
$$

Fine reads this way and objects that if the existence predicate is our tautologous predicate, then the statement "Flying mammals exist" would turn out to be trivially true, as it would be a logical truth. Yet, there are some doubts about this. If one adopts a free logic that restricts the rule of introduction of existential quantification in the familiar way, and there are independent reasons to do it, then it is not clear that the statement is a logical truth.

At any rate, another, more serious, objection to reading 1 is that a statement like "Unicorns exist" would turn out to be true - vacu- 
ously true, assuming that the domain of quantification does not contain unicorns.

One way of replying to this objection would be to replace the usual quantifiers of classical first-order predicate logic with generalized quantifiers, being thus able to block such undesirable assignments of truth-value; but we will leave the issue at this point.

Reading 2: Some flying mammals exist

$\exists \mathrm{x}(\mathrm{MVx} \wedge \exists \mathrm{yx}=\mathrm{y})$

We prefer this reading, which is clearly not a logical truth. The existence predicate is indeed in a sense tautological: nothing is added by it if the domain of quantification already contains at least one flying mammal. But that is what should be expected given the logical nature of our existence predicate.

Given the analysis proposed for general existence, general nonexistence has a straightforward rendering.

General Non-existence: Fs do not exist

$$
\forall \mathrm{x}(\mathrm{Fx} \rightarrow \neg \exists \mathrm{yx}=\mathrm{y})
$$

We close with an interesting observation. Take the symbolizations proposed for general existence and non-existence.

$$
\begin{aligned}
& \text { Fs exist } \\
& \exists \mathrm{x}(\mathrm{Fx} \wedge \exists \mathrm{yx}=\mathrm{y}) \\
& \text { Fs do not exist } \\
& \forall \mathrm{x}(\mathrm{Fx} \rightarrow \neg \exists \mathrm{y}=\mathrm{y})
\end{aligned}
$$

It turns out that they are logically equivalent to the simpler symbolizations one finds in logic textbooks, namely

$\exists \mathrm{xFx}$

$\neg \exists \mathrm{xFx}$.

João Branquinho

University of Lisbon, LanCog Group 


\section{References}

Evans, G. 1982. The Varieties of Reference, ed. by John McDowell. Oxford: Clarendon Press and New York: Oxford Unviversity Press.

Fine, K. 2009. The Question of Ontology. In Metametaphysics. New Essays on the Foundations of Ontology, ed. by David J. Chalmers, David Manley and Ryan Wasserman. Oxford: OUP, 157-77.

Frege, G. 1950. The Foundations of Arithmetic. A Logico-Mathematical Inquiry into the Concept of Number. Tr. by J.L. Austin. Oxford: Basil Blackwell.

Kaplan, D. 1979. Transworld heir lines. In The Possible and the Actual, ed. by M. Loux. Ithaca, NY: Cornell University Press, 88-109.

Kaplan, D. 1989a. Demonstratives. In Themes from Kaplan, ed. by Almog, J. Perry and H. Wettstein. Oxford: Oxford University Press, 481-563.

Kaplan, D. 1989b. Afterthoughts. In Themes from Kaplan, ed. by J. Almog, J. Perry and H. Wettstein. Oxford: Oxford University Press, 565-614.

Kripke, S. 1980. Naming and Necessity. Cambridge, MA: Harvard University Press.

Kripke, S. 2011. Vacuous Names and Fictional Entities. In Philosophical Troubles. S. Kripke, Collected Papers. Volume I. Oxford, Oxford University Press: 52-74.

Lewis, D.K. 1990. Noneism or Allism?, Mind 99: 23-31

McGinn, C. 2000. Logical Properties. Identity, Existence, Predication, Necessary Truth. Oxford: Clarendon Press.

Meinong, A. 1960. On the Theory of Objects. Translated by R. Chisholm, I. Levi and D. Terrell. In Realism and the Background of Phenomenology, ed. by R. Chisholm. Glencoe: The Free Press, 76-117.

Moore, G. E. 1936. Is Existence a Predicate? Proceedings of the Aristotelian Society, Supplementary Volume XV: 175-88. Reprinted in G.E. Moore, Philosophical Papers. London: George Allen and Unwin, 102-14.

Parsons, T. 1980. Non-existent Objects. New Haven, CT: Yale University Press.

Parsons, T. 1995. Are There Non-existent Objects. American Philosophical Quarterly, Vol. 19, No. 4, Oct., 1982, 365-371

Priest, G. 2005. Towards Non-Being. The Logic and Metaphysics of Intentionality. Oxford, OUP.

Quine, W. V. O. 1969. Existence and Quantification. In Ontological Relativity and Other Essays. New York: Columbia University Press, 91-113.

Quine, W. V. O. 1980. On What There Is. In From a Logical Point of View. Nine Logico-Philosophical Essays. $2^{\text {nd }}$ edition. Cambridge, Massachusetts and London, England: Harvard University Press.

Ramsey, F. P. 1925. Universals. Mind, New Series, Vol. 34, No. 136 (Oct., 1925), 401-417

Routley, R. 1980. Exploring Meinong's Jungle and Beyond: An Investigation of Noneism and the Theory of Items. Australian National University.

Russell, B. 1903. Principles of Mathematics. Cambridge, England, Cambridge University Press

Russell, B. 1905. On Denoting. Mind 14:479-93.

Russell, B. 1988. The Philosophy of Logical Atomism. In The Collected Papers of Bertrand Russell, Volume 8: The Philosophy of Logical Atomism and Other Essays, 1914-19. Ed. John Slater. London: Routledge, 155-244.

Salmon, N. 1987. Existence. In Philosophical Perspectives, 1: Metaphysics, ed. by James Tomberlin. Atascadero, Cal.: Ridgeview, 49-108. Reprinted in Metaphysics, Mathematics and Meaning: Philosophical Papers, Volume I. Oxford: Clarendon: 9-49.

Salmon, N. 1998. Nonexistence. Nous 32/3: 277-319. Reprinted in Metaphysics, 
Mathematics and Meaning: Philosophical Papers, Volume I. Oxford: Clarendon: 50-90.

Van Inwagen, P. 1977. Creatures of Fiction. American Philosophical Quarterly 14/4 (1977): 299-308

Van Inwagen, P. 2008. McGinn on Existence. Philosophical Quarterly, Volume 58 - Issue 230: 36-58

Williamson, T. 2013. Modal Logic as Metaphysics. Oxford: Oxford University Press. 